\title{
Infarktprophylaxe auf dem Klo?
}

\section{Schlechte Nachricht für Obstipationspatienten: Wer seltener Stuhlgang hat, scheint ein höheres Risiko zu tragen, an einer kardiovaskulären Krankheit zu sterben.}

_ Die chronische Obstipation ist ein häufiges Problem, das auch mit kardiovaskulären Erkrankungen, oxidativem Stress, erhöhter Karzinomprävalenz und geringerer Lebenserwartung in Verbindung gebracht wird.

Eine Langzeitstudie aus Japan stützt nun die Hypothese, dass mit dem häufigen Toilettengang auch Infarktprophylaxe betrieben wird. Im Rahmen einer Kohortenstudie an 45.112 Männern und Frauen zwischen 40 und 79 Jahren wurde die Defäkationsfrequenz anhand eines täglich selbst ausgefüllten Fragebogens bestimmt. Vier Kategorien - einmal täglich oder öfter, jeden zweiten Tag, jeden dritten Tag, noch seltener - wurden im
Rahmen einer Cox-Regression mit der kardiovaskulären Mortalität im Laufe von 13,3 Jahren Follow-up korreliert. In diesem Zeitraum waren 2.028 Personen an einer kardiovaskulären Erkrankung verstorben. Im Vergleich zur Gruppe, die täglich Stuhlgang hatte, war die kardiovaskuläre Gesamtmortalität in den beiden eher obstipierten Kohortengruppen um $21 \%$ bzw. $39 \%$ erhöht.

- Honkura Ket al. Defecation frequency and cardiovascular mortality in Japan: The Ohsaki cohort study. Atherosclerosis. 2016;246:251-6

\section{KOMMENTAR}

Über den Zusammenhang zwischen Defäkationsfrequenz und kardiovaskulärer Mortali- tät lässt sich natürlich trefflich spekulieren. $\mathrm{Na}$ heliegend wäre z. B., den Bewegungsmangel als verbindendes Glied anzusehen. Es ehrt die

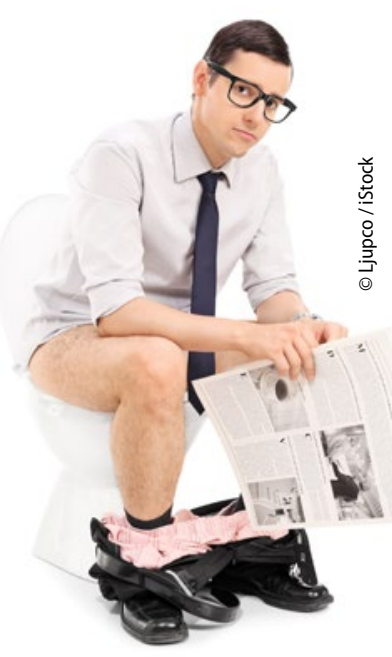
Autoren, dass sie ihre Daten nicht überinterpretieren, sondern sie vielmehr als hypothesengenerierend ansehen. In Framingham hat man sich um den Stuhlgang nicht gekümmert. Aber dort spricht man ja auch nie vom Klo, sondern geht lediglich etwas verschämt zum „bathroom". In Japan ist man da mit dem Ausdruck 便器 - wörtlich: „Exkrementvorrichtung" - schon konkreter.

Prof. Dr. med. H. S. FüeßI

\section{Hier steht eine Anzeige.}

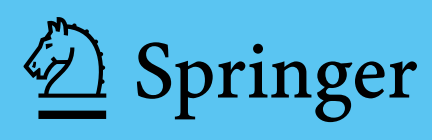

